\title{
Análise bibliométrica em controladoria dos artigos publicados no Congresso Brasileiro de Custos no período de 2011 a 2018
}

Devido à importância da controladoria para as organizações, diversos autores vêm publicando nessa temática. Esse estudo busca identificar o perfil dos artigos publicados com o tema controladoria no Congresso Brasileiro de Custos dentro do período de 2011 a 2018 . Trata-se de uma pesquisa descritiva com abordagem quantitativa e bibliométrica do tipo levantamento. A análise de dados, da amostra de 58 artigos, foi realizada por meio de técnicas bibliométricas. Os resultados indicam que a quantidade de artigos está diminuindo ao longo dos anos e Rogério Lunkes, Augusto Cabral, Marcus Machado, Maria Peter, Maria Pessoa e Sandra Santos foram os autores com maior número de publicações. Viu-se ainda que as instituições UFC, UFSC, UEM, UFBA tiveram mais autores vinculados, logo, destaque para às regiões Nordeste e Sul. A respeito da temática dos artigos constatou-se que custos como ferramenta para o planejamento, controle e apoio a decisões seguido de metodologias de ensino e pesquisa em custos foram os que tiveram mais artigos publicados no CBC. As palavras-chaves mais referenciadas foram: produção científica, bibliometria, contabilidade, práticas de controladoria, controladoria, controller e gestão de custos. Relativo à metodologia viu-se que o objetivo de pesquisa mais utilizado foi descritivo (74\%), a estratégia de pesquisa com maior destaque foi o levantamento (43\%) e $48 \%$ dos artigos possuíam abordagem qualitativa.

Palavras-chave: Bibliometria; Controladoria; Congresso Brasileiro de Custos.

\section{Bibliometric analysis in controllership of articles published in the Brazilian Congress on Costs from 2011 to 2018}

\begin{abstract}
Due to the importance of controllership for organizations, many authors have been publishing in this area. This article aims to identify the profile of the articles published with the theme Controlling at the Brazilian Congress of Costs (CBC), within the period from 2011 to 2018. It is a descriptive research with quantitative and bibliometric approach of the survey type. Data analysis of the sample of 58 articles was performed using bibliometric techniques. The results indicate that the number of articles has been decreasing over the years and the authors with the highest number of publications were Rogério Lunkes, Augusto Cabral, Marcus Machado, Maria Peter, Maria Pessoa and Sandra Santos. UFC, UFSC, UEM and UFBA institutions also had more authors linked to the Northeast and South regions. Regarding the article, it was observed that costs as a tool for planning, controlling and supporting decisions followed by methodologies of teaching and research in costs were the ones that had more articles published in the CBC. The most referenced keywords were scientific production, bibliometrics, accounting, controlling practices, controlling, controller and cost management. Regarding methodology, we found that the most used research objective was descriptive (74\%), the research strategy with the most emphasis was survey (43\%) and $48 \%$ of the articles had a qualitative approach.
\end{abstract}

Keywords: Bibliometrics; Controllership; Brazilian Congress of Costs.

Topic: Contabilidade Gerencial

Reviewed anonymously in the process of blind peer.
Received: 07/01/2021

Approved: 23/03/2021
Ana Luiza Monteiro Bastos Ornellas (ic) Instituto Federal de Minas Gerais, Brasil http://lattes.cnpq.br/4096831893245408 http://orcid.org/0000-0001-8052-2957 ana luizamonteiro@hotmail.com

Rayssa Rayane Rocha Rosário Araújo (iD Instituto Federal de Minas Gerais, Brasil http://lattes.cnpq.br/6801504163441371 http://orcid.org/0000-0002-8522-3013 rayssa.rosario.sud@gmail.com

Lívia Maria de Pádua Ribeiro (i)

Instituto Federal de Minas Gerais, Brasil http://lattes.cnpq.br/3836203930867479 http://orcid.org/0000-0002-5271-9397 livia.padua2014@gmaill.com

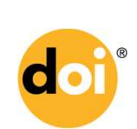

DOI: 10.6008/CBPC2179-684X.2021.001.0025

\author{
Uajará Pessoa Araújo (iD \\ Instituto Federal de Minas Gerais, Brasil \\ http://lattes.cnpq.br/3898285928077336 \\ http://orcid.org/0000-0003-1288-1514 \\ uajara@yahoo.com.br \\ Bárbara Gabrielle Silva (iD) \\ Instituto Federal de Minas Gerais, Brasil \\ http://lattes.cnpq.br/6525272066238635 \\ http://orcid.org/0000-0002-4086-014X \\ barbarags96@hotmail.com
}

\section{Referencing this:}

ORNELLAS, A. L. M. B.; ARAUJO, R. R. R. R.; RIBEIRO, L. M. P.; ARAÚJO, U. P.; SILVA, B. G.. Análise bibliométrica em controladoria dos artigos publicados no Congresso Brasileiro de Custos no período de 2011 a 2018. Revista Brasileira de Administração Científica, v.12, n.1, p.303313, 2021. DOI: http://doi.org/10.6008/CBPC2179$\underline{684 X .2021 .001 .0025}$ 


\section{INTRODUÇÃO}

Diversas organizações no mercado atual estruturaram um bom controle financeiro a fim de otimizar os resultados e reduzir desperdícios. Um dos instrumentos que auxilia nesse processo de otimização é a controladoria que se torna imprescindível para a gestão eficiente e moderna das empresas. A controladoria pode interferir na produtividade, rentabilidade, diminuição de erros e análise de resultados (OLIVEIRA et al., 2018b). Percebe-se, portanto, que as práticas de controladoria se fazem importantes na continuidade da organização.

De modo geral há duas visões sobre o conceito de controladoria, alguns autores a conceituam como órgão administrativo e outros como um conjunto de doutrinas e conhecimentos. Nesse sentido, a controladoria como órgão administrativo, possui a função de assegurar a existência de informações necessárias para tomada de decisão, além de auxiliar os gestores e contribuir para eficácia empresarial. Já como um conjunto de doutrinas e conhecimentos, compete a controladoria "estudar o comportamento e controle econômico das riquezas das empresas, em face das ações humanas" (MOSIMAUM et al., 2009). Para Oliveira et al. (2018a), a Controladoria é relevante para a gestão das organizações por ter seu conhecimento construído com base na interação entre diferentes conteúdos.

Em vista da importância desse assunto para as organizações e possível contribuição de artigos nessa área, tanto para o conhecimento científico quanto para a atuação profissional dos agentes envolvidos na gestão das organizações, o presente artigo buscou responder ao seguinte questionamento de pesquisa: Qual o perfil dos artigos com a temática controladoria inseridos no Congresso Brasileiro de Custos (CBC) dentro do período de 2011 a 2018? Logo, a partir dos dados disponíveis no site do CBC, realizou-se um estudo bibliométrico a fim de ampliar os conhecimentos na área das ciências sociais aplicadas, especificamente, no tema controladoria.

Nesse sentido, o objetivo principal deste estudo foi realizar uma bibliometria de artigos acadêmicos publicados no CBC no período de 2011 a 2018, sobre o tema de controladoria. Como objetivos específicos, o artigo buscou: selecionar os artigos desse período que possuem como temática a controladoria; identificar as principais técnicas de pesquisa e abordagens de metodologia utilizadas nos artigos selecionados; apurar quais autores e instituições têm maior participação nos artigos acadêmicos relativo à controladoria no CBC; identificar as palavras-chaves mais recorrentes e, por fim, apontar qual o enfoque dos artigos publicados.

Alguns trabalhos com pontos semelhantes a essa pesquisa já foram publicados, com a destaque ao trabalho de Ribeiro et al. (2015) que realizou um estudo bibliométrico em controladoria no Congresso Brasileiro de Custos no período de 2004 a 2010. Entretanto, o filtro, algumas variáveis de pesquisas e o período são diferentes. Bastos et al. (2010), também já publicaram sobre o assunto, sendo a maior diferença o período e a quantidade de eventos científicos estudada.

A escolha de se estudar o período de 2011 a 2018 foi proposital, uma vez que já existe um estudo de bibliometria em controladoria, dos autores Ribeiro et al. (2015) que analisam o período de 2004 a 2010 do CBC. Sendo assim, o presente artigo pode contribuir para complementar os estudos de Ribeiro et al. (2015) 
e de outros autores que também estudaram a controladoria por meio da bibliometria, como Bastos et al. (2010), Vasconcelos et al. (2017) e Albuquerque et al. (2013). Adicionalmente, esse trabalho pode possibilitar a comparação dos resultados.

Esse artigo foi estruturado em cinco partes. A primeira refere-se à introdução, a partir da identificação do objetivo desse estudo e sua contextualização. A segunda apresenta referencial teórico com base na literatura que aborda a conceituação e função da controladoria e do controller. A terceira parte trata da metodologia de pesquisa. A quarta apresenta os dados e resultados obtidos. E, por fim, têm-se as considerações finais desse estudo.

\section{REVISÃO TEÓRICA}

\section{Conceituação de controladoria e controller}

Na conceituação de controladoria não há um consenso devido ao fato de envolver várias funções, entretanto, há uma certa concordância relativa ao objetivo que seria colocar em prática a missão da empresa (RIBEIRO et al., 2015). Há correntes diferentes que conceituam controladoria, algumas defendem que é um órgão administrativo, outras um ramo de conhecimento. Há ainda as que definem como uma função gerencial (OLIVEIRA et al., 2018a).

A controladoria pode ser entendida como uma unidade administrativa que utiliza dos conhecimentos da Ciência Contábil, em síntese, seria um fruto da Contabilidade. Nessa perspectiva é uma "unidade administrativa dentro da empresa que, através da Ciência Contábil e Sistema de Informação da Controladoria, é responsável pela coordenação da gestão econômica do sistema de empresa" (PADOVEZE, 2010). Complementarmente:

Pode-se entender controladoria como o departamento responsável pelo projeto, elaboração, implementação e manutenção do sistema integrado de informações operacionais, financeiras e contábeis de determinada entidade, com ou sem fins lucrativos, sendo considerada por muitos autores como o atual estágio evolutivo da Contabilidade. (OLIVEIRA et al., 2014)

Como órgão administrativo, possui "importante capital para sobrevivência, crescimento e consolidação das empresas" (MORANTE et al., 2008). E fundamenta-se no modelo de gestão, tendo um papel fundamental na assessoria da alta administração de organizações grande porte, de modo geral. Nesse sentido, não possui a finalidade de controlar as áreas, mas sim prestar assessoria no controle executado pela cúpula administrativa (MOSIMAUM et al., 2009). O objetivo principal é fornecer informações que auxiliaram na tomada de decisão e assim melhorar a eficácia gerencial (FIGUEIREDO et al., 2008).

Já na perspectiva de área do conhecimento humano possui "fundamentos, conceitos, princípios e métodos oriundos de outras ciências". Seria, portanto, um modelo conceitual teórico originado da contabilidade e de outras ciências como administração, economia, psicologia entre outras (MOSIMAUM et al., 2009). A controladoria pode ser vista ainda como um instrumento de controle e gerenciamento de atividades. Assim, atribui-se que é vital dar suporte e subsidiar os gestores da empresa (OLIVEIRA et al., 2014). Para Oliveira et al. (2018), a Controladoria está se tornando parte da alta administração, e é 
denominado controller o profissional que exerce as atividades relacionadas a Controladoria.

Ao se estudar Controladoria, muito se discute sobre quem é o Controller. Conforme a estrutura de cargos de cada organização, o título de controller tem sido aplicado a diferentes cargos possuindo responsabilidades e remunerações variando de acordo com o porte da empresa e o setor que se insere. Esse profissional precisa ser multifuncional isso inclui não ter somente experiências em contabilidade, mas também em finanças e administração (OLIVEIRA et al., 2014).

A Controladoria precisa ser conduzida por profissional experiente, com larga vivência em finanças empresariais e uma particular habilidade no relacionamento com os responsáveis pela gestão das diversas áreas funcionais da organização. Este profissional é, por vezes, é identificado pela designação de controller, ou seja, controlador. (MORANTE et al., 2008)

De modo geral, o controller responde a alta administração. Trata-se de um profissional que processa uma grande variedade de informações a respeito do desempenho empresarial e possui a função de analisar e propor soluções com o intuito de cumprir com os objetivos que foram estabelecidos. Nesse sentido, suas atribuições vão além das funções do tesoureiro (PADOVEZE, 2010).

\section{Funções da controladoria e do controller}

De acordo com Beuren et al. (2013), "a controladoria pode ser definida mediante a relação das funções do controller e as funções da controladoria". Porém, a respeito das funções da controladoria e do controller, Oliveira et al. (2014) consideram que não existe uma clara definição.

O controller deve ter uma postura atuante no qual antecipe adversidades, apresente soluções, controle internamente e tenha capacidade de gerir as informações (ALBUQUERQUE et al., 2013). Assim, tem a função de gerir a informação que serão úteis na direção e controle dos gestores da organização, ou seja, tem mais o papel de assessorar aos gestores que tomar as decisões por eles (BASTOS et al., 2010).

Segundo Dani et al. (2018), "para apoiar o processo decisório nas organizações, as informações precisam ser geradas de modo a considerar, especialmente, as características de tempestividade e utilidade". A Controladoria assegura a coleta de dados relevantes envolvendo todo o sistema organizacional, desde as áreas operacionais até as administrativas, gerando informações tempestivas para sustentar a tomada de decisão (MONTEIRO et al., 2015).

O profissional da Controladoria além de ter funções contábeis como a supervisão de documentos financeiros, possui ainda funções gerenciais (FIGUEIREDO et al., 2008). Já a controladoria possui diversas funções, entre elas, dar apoio a gestão além de auxiliar na "avaliação de desempenho, o monitorando e a orientação adequada ao estabelecimento de padrões e avaliações do resultado de seus serviços" (ALBUQUERQUE et al., 2013).

O controller precisa ter um olhar sistêmico para unir e reportar informações de planejamento e controle úteis a fim de nortear o processo decisório dos gestores. As responsabilidades desse profissional podem ser analisadas em três perspectivas:

No planejamento estratégico, cabe ao controller assessorar o principal executivo e os demais gestores na definição de estratégia, fornecendo informações rápidas e confiáveis sobre a empresa. No planejamento operacional, cabe a ele desenvolver um modelo de 
planejamento baseado no sistema de informação atual, integrando-o para a otimização das análises. No controle, cabe ao responsável pela Controladoria exercer a função de perito ou juiz, conforme o caso, assessorando de forma independente na conclusão dos números e das medições quantitativas e qualitativas (índice de qualidade). (OLIVEIRA et al., 2014)

Em sua pesquisa, Lunkes et al. (2010) buscaram identificar o perfil e as funções do controller e identificaram a uniformidade de funções relacionadas ao gerenciamento da contabilidade, orçamento, controle fiscal e tributário, planejamento estratégico, relatórios gerenciais e gerenciamento da tesouraria.

Verifica-se então que a Controladoria como órgão administrativo tem como principais funções o controle e fornecimento de informações para tomada de decisão e o controller é o profissional que atua no processo de execução da Controladoria.

\section{METODOLOGIA}

O presente trabalho é um estudo quantitativo, assim, objetiva-se quantificar os dados. A pesquisa quantitativa baseia-se em amostras grandes e representativas em pode-se analisar por meio de estatística (MALHOTRA, 2005), possui ainda caráter descritivo, nesse sentido, o foco é a descrição de uma variável (GIL, 2002).

É um artigo teórico e empírico, já que inicialmente, buscou-se realizar uma pesquisa na literatura a respeito da conceituação e funções da controladoria e do controller. Para depois, realizar uma pesquisa de caráter bibliográfico no sítio do CBC. Portanto, a base de dados é constituída pelos artigos publicados no CBC, nesse sentido, utiliza-se fontes primárias.

O trabalho é um estudo quantitativo de caráter descritivo, sendo o universo de pesquisa os artigos publicados no CBC entre 2011 a 2018, utilizando assim um corte transversal. O corte transversal, justifica-se pela intenção de dar continuidade ao trabalho de Ribeiro et al. (2015) que analisaram as publicações do mesmo congresso no período de 2004 a 2010.

Para análise desse artigo foi retirada uma amostra constituída de 58 artigos da temática controladoria. Portanto, esse artigo busca analisar os artigos com a temática controladoria publicados no CBC de 2011 a 2018.

A forma com que os artigos foram selecionados se diferenciou do trabalho de Ribeiro et al. (2015), já que a partir de 2011 o CBC não contava mais com a área temática específica de Controladoria. Portanto, nessa pesquisa foram levantados os trabalhos que tinham a palavra controladoria no resumo ou título. Esse filtro é válido por reduzir o erro de classificação, levando em consideração que artigos voltados para a área de controladoria necessariamente irão mencionar a palavra em seu título ou resumo.

A primeira fase da coleta de dados foi a sondagem de trabalhos anteriores que já realizaram análises bibliométricas com a temática controladoria, levantou-se os estudos de Ribeiro et al. (2015) e Bastos et al. (2010). Sendo que esses trabalhos deram suporte para as análises bibliométricas desse artigo.

Posteriormente, utilizando-se de técnicas bibliográficas levantou-se as seguintes variáveis no site do CBC: autores que mais publicaram; os autores mais citados; as instituições que mais publicaram; número de integrantes por artigos; tipo de pesquisa; abordagem técnica de coleta de dados e área específica do evento 
que os artigos foram publicados.

Uma vez que os dados são obtidos é preciso analisá-los e interpretá-los. Nessa etapa, foram apresentados cálculos estatísticos descritivos, entre eles análise de frequência absoluta e porcentagem. Esses cálculos estatísticos foram realizados com o apoio do software Excel. Esse momento caracteriza-se pela análise, ou seja, é o período no qual o pesquisador a partir dos dados estatísticos busca levantar respostas e relações (MARCONI et al., 2010).

\section{RESULTADOS}

Essa seção apresenta uma análise quantitativa dos dados levantados. O período analisado foi um intervalo de 8 anos que inclui todos os artigos publicados no CBC nos anos de 2011 a 2018 que continha a palavra Controladoria no título ou resumo. Nesse sentido, abrangeu do XVIII Congresso Brasileiro de Custos ao XXV CBC.

Os anos que tiveram maior número de publicações foram o de 2012 e 2013, já que juntos representam quase $50 \%$ da amostra de 58 artigos. No geral, pode-se concluir que a quantidade de publicações está diminuindo de modo considerável.

Tabela 1: Quantidade de artigos publicados por ano.

\begin{tabular}{lll}
\hline Ano & Quantidade de artigos & Porcentagem \\
\hline 2011 & 9 & $16 \%$ \\
2012 & 14 & $24 \%$ \\
2013 & 14 & $24 \%$ \\
2014 & 9 & $16 \%$ \\
2015 & 3 & $5 \%$ \\
2016 & 4 & $7 \%$ \\
2017 & 2 & $3 \%$ \\
2018 & 3 & $5 \%$ \\
\hline Total & 58 & $100 \%$ \\
\hline
\end{tabular}

Na Tabela 2 aparecem os autores que mais publicaram no período de 2011 a 2018 no Congresso Brasileiro de Custos. Com destaque para Rogério Lunkes (4 artigos) e Augusto Cabral, Marcus Machado, Maria Peter, Maria Pessoa e Sandra Santos (todos publicaram 3 artigos). Houveram ainda, 9 autores que publicaram dois artigos no período e os demais publicaram apenas um artigo.

Tabela 2: Quantidade de artigos publicados por autor.

\begin{tabular}{ll}
\hline Autor & Quantidade de artigos publicados \\
\hline Rogério João Lunkes & 4 \\
Augusto Cézar Aquino Cabral & 3 \\
Marcus Vinicius Veras Machado & 3 \\
Maria da Gloria Arrais Peter & 3 \\
Maria Naiula Monteiro Pessoa & 3 \\
Sandra Maria dos Santos & 3 \\
Adriano Leal Bruni & 2 \\
Amanda de Oliveira Gomes & 2 \\
Antonio Barbosa Batista & 2 \\
Christian Mascarenhas Andrade & 2 \\
Darci Schnorrenberger & 2 \\
Marcos Antônio de Souza & 2 \\
Mauricio Farias Cardoso & 2 \\
Naiana Vasconcelos Silva Cruz & 2 \\
Nathália Helena Fernandes Laffin & 2 \\
Demais autores & 1 \\
\hline
\end{tabular}


Além dos autores que mais publicaram, foram levantadas as instituições a que esses autores estavam associados. Como há autores que publicaram mais de uma vez é bem provável que isso tenha colaborado para a concentração das publicações em certas instituições.

A instituição que teve maior destaque foi a Universidade Federal do Ceará (UFC) que foi referenciada 29 vezes, em seguida, a Universidade Federal de Santa Catariana (UFSC) com 15 ocorrências, Universidade Estadual de Maringá (UEM) com 14 e Universidade Federal da Bahia (UFBA) com 11. Portanto, a região Nordeste e Sul foram as que alçaram maior destaque. Viu-se também que 28 instituições apresentaram apenas um autor associado e 4 autores não identificaram qual a instituição que possui vínculo. Conforme Tabela 3.

Tabela 3: Quantidade de autores vinculados a cada instituição.

\begin{tabular}{ll}
\hline Instituição & Quantidade de autores \\
\hline UFC & 29 \\
UFSC & 15 \\
UEM & 14 \\
UFBA & 11 \\
USP & 8 \\
UFMS & 8 \\
UFMG & 8 \\
UFRJ & 7 \\
UNISINOS e UEPB & 6 \\
Unilasalle e UFSJ & 6 \\
UNIR, UNIOESTE, UNIFAL, UFV, UFU, UFJF, UEFS, PUCSP e FECAP & 4 \\
UNISUL, UFRGS, UERN, UEL, UDESC, FURB, FARN, FAINOR e FAI & 3 \\
Demais instituições (28) & 2 \\
\hline
\end{tabular}

Na área de custos empresariais, o Congresso Brasileiro de custos é principal evento, além de ser um importante divulgador das produções acadêmicas, segundo o sítio do anal. A fim de facilitar o enquadramento dos artigos, o CBC define 8 áreas temáticas, conforme Quadro 1.

Quadro 1: Áreas temáticas.

\begin{tabular}{ll}
\hline Área temática & Assuntos \\
\hline Metodologia de ensino e pesquisa em custos. & $\begin{array}{l}\text { Instrumentos, técnicas e métricas para aperfeiçoar o estudo de custos. } \\
\text { Custos como ferramenta para o planejamento, } \\
\text { Metodologias de custeio aplicadas no controle, gestão e tomada de } \\
\text { controle e apoio a decisões. }\end{array}$ \\
Métodos quantitativos aplicados à gestão de custos. & $\begin{array}{l}\text { Utilização de conhecimentos matemáticos, estatísticos e de pesquisa } \\
\text { operacional associado a custos. }\end{array}$ \\
$\begin{array}{l}\text { Estuda metodologias de custos voltadas para empresas e terceiro setor. } \\
\text { Custos aplicados ao setor privado e terceiro setor. }\end{array}$ & $\begin{array}{l}\text { Custeio adaptado ao setor público } \\
\text { Contribuições teóricas para determinação e a gestão } \\
\text { de custuda o aperfeiçoamento da determinação, mensuração e e } \\
\text { Abordagens contemporâneas de custos. }\end{array}$ \\
Casos empresariais. & $\begin{array}{l}\text { Estuda as tendências na área. } \\
\text { Apresenta casos empresariais com o tema custo, possui formato } \\
\text { diferenciado das outras temáticas. }\end{array}$ \\
\hline
\end{tabular}

Na pesquisa levantou-se que a área temática com maior número de artigos foi custos como ferramenta para o planejamento, controle e apoio a decisões com 43\% das publicações (25 artigos) seguido por metodologias de ensino e pesquisa em custos com 26\% (15 artigos). Não houveram publicações nas áreas de métodos quantitativos aplicados a gestão de custos e casos empresariais. Tanto contribuições teóricas para a determinação e a gestão de custos quanto custos aplicados ao setor privado e terceiro setor representaram apenas 3\% dos artigos publicados. Esses dados podem ser visualizados na Tabela 4. 
Tabela 4: Quantidade de artigos por área temática.

\begin{tabular}{lll}
\hline Áreas temáticas & Quantidade de artigos & Porcentagem \\
\hline Metodologias de ensino e pesquisa em custos & 15 & 26 \\
Custos como ferramenta para o planejamento, controle e apoio a decisões & 25 & 43 \\
Métodos quantitativos aplicados à gestão de custos & 0 & 0 \\
Custos aplicados ao setor privado e terceiro setor & 2 & 3 \\
Custos aplicados ao setor público & 7 & 12 \\
Contribuições teóricas para a determinação e a gestão de custos & 2 & 3 \\
Abordagens contemporâneas de custos & 7 & 12 \\
Casos Empresariais & 0 & 0 \\
\hline Total & 58 & 100 \\
\hline
\end{tabular}

Para entender mais afundo quais os assuntos tratados em cada artigo foram levantas as palavraschaves. Percebeu-se que alguns autores utilizaram palavras parecidas para expressar a mesma ideia, porém a fim de evitar erros na classificação das palavras chaves não foram alteradas e agrupadas mesmo que pareçam sinônimas, com exceção das palavras contabilidade e ciências contábeis que foram agrupadas na categoria contabilidade.

Verificou-se que 'produção científica' constando em 6 artigos e 'bibliometria', 'contabilidade' e 'práticas de controladoria' em 5 artigos foram as palavras-chaves que mais apareceram nas publicações. Tanto 'controladoria', 'controller' e 'gestão de custos' apareceram como palavras-chaves de 4 artigos, conforme Tabela 5.

Tabela 5: Palavras-chaves mais referenciadas nos artigos.

\begin{tabular}{lc}
\hline Palavras-chaves & Quantidade \\
\hline Produção Científica & 6 \\
Bibliometria, Contabilidade e Práticas de Controladoria & 5 \\
Controladoria, Controller e Gestão de custos & 4 \\
Contabilidade de Custos, Contabilidade Gerencial, Custos, Funções da Controladoria e Gestão Estratégica de Custos & 3 \\
Controle Interno, Ensino Superior, Estudo de Caso, Funções, Gestão, Instituições Privadas de Ensino Superior, \\
Logística Reversa, Mercado de Trabalho, Segurança Privada e Universidades Federais. & 2 \\
\hline
\end{tabular}

Tabela 6: Artigos segundo a metodologia.

\begin{tabular}{llll}
\hline Critério & Classificação & Quantidade de artigos & Porcentagem \\
\hline & Descritivo & 43 & $74 \%$ \\
& Descritivo-exploratório & 6 & $10 \%$ \\
Objetivo da pesquisa & Exploratório & 8 & $14 \%$ \\
& Básico & 0 & $0 \%$ \\
& Experimental & 0 & $0 \%$ \\
& Explicativa-descritivo & 1 & $2 \%$ \\
\hline Total & & 58 & $100 \%$ \\
\hline & Documental & 16 & $22 \%$ \\
Estratégia da pesquisa & Levantamento & 31 & $43 \%$ \\
& Estudo de caso & 11 & $15 \%$ \\
& Bibliográfico & 14 & $20 \%$ \\
\hline Total & Laboratório & 0 & $0 \%$ \\
\hline \multirow{2}{*}{ Abordagem do problema } & Pesquisa-ação & 0 & $0 \%$ \\
\hline Total & & 72 & $100 \%$ \\
\hline & Quantitativo & 19 & $33 \%$ \\
\hline
\end{tabular}

Por fim, foram analisados os artigos segundo a sua metodologia. Para isso utilizou-se os seguintes critérios: objetivo da pesquisa, estratégia da pesquisa e abordagem do problema. Relativo ao objetivo de pesquisa constatou-se que maioria das pesquisas possuem caráter descritivo (74\%) seguido do exploratório 
(14\%). Houve ainda a mescla do objetivo, por exemplo, 6 artigos foram descritivo-exploratório e um explicativo-descritivo.

Já na categoria estratégia de pesquisa constatou-se que a técnica mais utilizada é o levantamento (43\%) seguido de documental (22\%) e bibliográfica (20\%). Como é comum os autores utilizarem mais de uma estratégia o total nessa categoria ultrapassa os 58 artigos estudados, entretanto, ao se calcular a porcentagem pode-se verificar a quantidade relativa de cada classificação no critério estratégia de pesquisa.

No critério abordagem do problema constatou-se que $48 \%$ dos artigos possuíam abordagem qualitativa, 33\% quantitativa e 19\% quali-quantitativa. Alguns artigos não apresentam diretamente essa classificação. Logo, a partir dos conceitos sobre a classificação da abordagem de Gil (2002) foi possível enquadrar os artigos de acordo com a abordagem utilizada, conforme Tabela 6.

\section{DISCUSSÃO}

A partir de 2011 o CBC adotou um novo enquadramento dos artigos que subdivide os artigos em 8 áreas temáticas, superando o modelo antigo que os dividi em 16 temáticas. Ribeiro et al. (2015) utilizando a divisão antiga realizaram um estudo bibliométrico no tema controladoria (na época existia essa categoria). Entretanto, desde 2011 essa categoria foi extinta e os artigos com a tema controladoria foram reorganizados em uma das oito novas categorias.

Nesse sentido, para se estudar os artigos publicados com a temática controladoria no Congresso Brasileiro de Custos não basta apenas identificar os artigos da categoria temática controladoria, mas sim utilizar um filtro que rastreia a palavra controladoria no título, resumo ou texto completo. Ribeiro et al. (2015) ao analisarem as publicações do CBC no período de 2004 a 2010 encontraram 340 artigos, entretanto, o presente artigo que considerou o período de 2011 a 2018 utilizando a busca por palavra-chave, encontrou 58.

Apesar da discrepância do volume ainda é válido fazer comparações entre os resultados. Em comparação com o trabalho de Ribeiro et al. (2015), verificou-se que nos anos de 2011 a 2018 houve maior oscilação na quantidade de publicações por ano. Sobre o número de autores por trabalho publicado de 2004 a 2010 os autores encontraram a predominância de 2 (32,35\%), 3 (33,24\%) e 4 (18,53\%), já essa pesquisa encontrou $2(16,07 \%), 3$ e $4(25 \%)$ e $5(23,21 \%)$.

A respeito dos autores que mais publicaram, identificou-se que dos 15 que mais publicaram dentro do período de 2011 a 2018, 3 também foram destaque em número de publicações dos anos de 2004 a 2011. São eles: Rogério João Lunkes, Marcus Vinicius Veras Machado e Darci Schnorrenberger. Já na apuração das instituições que mais destacaram em publicações de 2011 a 2018 foram UFC, UFSC, UEM e UFBA já de 2004 a 2010 foram FURB, UFSC e USP.

Esse artigo também apresentou divergências em relação a alguns tipos de categorias de análises, quando comparado ao estudo de Ribeiro et al. (2015). No presente trabalho identificou-se as principais técnicas de pesquisa e abordagens de metodologia utilizadas nos artigos selecionados e as palavras-chaves mais recorrentes que não foram analisados por Ribeiro et al. (2015). Outra divergência é que nesse artigo não 
se buscou identificar os tipos de referências bibliográficas utilizadas nos trabalhos selecionados e os autores e obras mais referenciadas que foram categorias presentes no estudo anterior.

Adicionalmente, esse artigo evidenciou lacunas relativas a temática dos artigos, já que na área temática 'Métodos quantitativos aplicados à gestão de custos', 'Casos Empresariais', 'Contribuições teóricas para a determinação e a gestão de custos' e 'Custos aplicados ao setor privado e terceiro setor' quase não tiveram publicações e se tiveram foram em número reduzido. Nesse sentido, evidencia oportunidades para publicações com essas temáticas.

Por se tratar de uma bibliometria a análise de dados foi quantitativa com uma quantidade reduzida de dados, sendo isso o maior fator limitante. Nesse sentido, impossibilita generalizações dos resultados. Outro fator limitante é a utilização de apenas um banco de dados, entretanto o banco de dados gerados pelas publicações no CBC presume-se ser constituído por artigos de qualidade já que é o principal evento no Brasil relacionado à área de custos empresariais. Por fim, vale expor que se faz interessante a utilização de outras bases de dados, por exemplo, Congresso USP de Controladoria e Contabilidade como também análise de publicações em periódicos em vez de congressos.

\section{CONCLUSÕES}

Este estudo buscou identificar o perfil dos artigos publicados no CBC dentro do período de 2011 a 2018. Foi constatado que a quantidade de artigos está diminuindo ao longo do tempo e os autores que mais publicaram foram Rogério Lunkes, Augusto Cabral, Marcus Machado, Maria Peter, Maria Pessoa e Sandra Santos. Viu-se também que a UFC, UFSC, UEM, UFBA foram as instituições que tiveram mais autores vinculados, dando destaque para a região Nordeste e Sul.

Relativo à temática dos artigos observou-se que custos como ferramenta para o planejamento, controle e apoio a decisões seguido de metodologias de ensino e pesquisa em custos foram os que tiveram mais publicações. Já as palavras-chaves mais referenciadas foram: produção científica, bibliometria, contabilidade, práticas de controladoria, controladoria, controller e gestão de custos.

Quanto análise da metodologia dos artigos viu-se que o objetivo de pesquisa mais utilizado foi descritivo (74\%) seguido do exploratório (14\%). Já na categoria estratégia de pesquisa o levantamento (43\%) seguido de documental (22\%) e bibliográfica (20\%) foram os que tiveram maior destaque. Relativo à abordagem do problema percebeu-se que $48 \%$ dos artigos possuíam abordagem qualitativa, 33\% quantitativa e $19 \%$ quali-quantitativa.

Em síntese, os resultados encontrados na pesquisa demonstram que mesmo sendo um tema relevante para a área de gestão e custos nas organizações, a temática de controladoria perdeu destaque dentro das publicações no CBC entre os anos de 2011 a 2018. Por fim, sugere-se a realização de uma pesquisa mais ampla que abranja outros congressos e revistas, nacionais e internacionais a fim de comparar os resultados. 


\section{REFERÊNCIAS}

ALBUQUERQUE, L. S.; LIMA, A. P.; REGO, T. F.; CARVALHO, J. R. M.. Análise bibliométrica dos artigos sobre controladoria publicados no congresso USP de controladoria e contabilidade no período de 2004 a 2010. Revista

Evidenciação Contábil e Finanças, v.1, n.2, 2013.

BASTOS, E. C.; BEUREN, I. M.. Inserção da Controladoria em Artigos Publicados em Eventos Científicos Nacionais. Revista de Contabilidade da UFBA, Salvador, v.4, n.1, p.4-22, 2010.

BEUREN, I. M.; UTZIG, M. J. S.; KLOEPPEL, N. R.. Impacto da integração do sistema de controle gerencial na eficácia da controladoria: um estudo nas empresas do setor elétrico da BM\&FBovespa. Revista Eletrônica de Ciência

Administrativa, v.12, n.3, p.273-287, 2013.

DANI, A. C.; BEUREN, I. M.. Mudanças na Controladoria com o Processo de Convergência às Normas Internacionais de Contabilidade. Revista Contabilidad y Negocios, v.13, n.24, p.20-41, 2018.

FIGUEIREDO, S.; CAGGIANO, P. C.. Controladoria: teoria e prática. 4 ed. São Paulo: Atlas, 2008.

GIL, A. C.. Como elaborar projetos de pesquisa. 4 ed. São Paulo: Atlas, 2002.

LUNKES, R. J.; BORGERT, A.; CUNHA, L. C.; FERRARI, M. J.. O perfil do controller sob a ótica do mercado de trabalho nacional. In: CONGRESSO ANPCONT, 4. Anais. 2010.

MALHOTRA, N. K.. Introdução à pesquisa de marketing. São Paulo: Pearson Prentice Hall, 2005.

MARCONI, M. A.; LAKATOS, E. M.. Técnicas de pesquisa: planejamento e execução de pesquisas, amostragens e técnicas de pesquisa, elaboração, análise e interpretação de dados. 7 ed. São Paulo: Atlas, 2010.
MONTEIRO, E. L. M.; TAGAMI, M. Y.; COSTA, P. C.; GOMES, A.; LAMEU, M. A.; LIMA, I. G.. A controladoria e o controller no processo de gestão organizacional. Revista Gestão em Foco, São Paulo, p.66-74, 2015.

MORANTE, A. S.; JORGE, F. T.. Controladoria: análise financeira, planejamento e controle orçamentário. São Paulo: Atlas, 2008.

MOSIMAUM, C. P.; FISH, S.. Controladoria: seu papel na administração de empresas. 2 ed. São Paulo: Atlas, 2009.

OLIVEIRA, C. P.; OLIVEIRA, C. P.; RODRIGUES, F. H.; MENDONÇA, F. M.; RIBEIRO, L. M. P.. Análise dos Conteúdos da Disciplina de Controladoria nos Cursos de Ciências Contábeis em Instituições de Ensino Superior em Minas Gerais. In: CONGRESSO NACIONAL DE ADMINISTRAÇÃO E CONTABILIDADE-ADCONT, 9. Anais. 2018a.

OLIVEIRA, G. B.; OLIVEIRA, R. A.. A importância da controladoria na percepção dos gestores: um estudo dirigido a uma empresa do meio oeste catarinense. In: ANUÁRIO PESQUISA E EXTENSÃO UNOESC JOAÇABA. Anais. 2018b.

OLIVEIRA, L. M.; PEREZ JUNIOR, J. H.; SILVA, C. A. S.. Controladoria estratégica: textos e casos práticos com solução. 10 ed. São Paulo: Atlas, 2014.

PADOVEZE, C. L.. Controladoria básica. 2 ed. São Paulo: Cengage Learning, 2010.

RIBEIRO, S. P.; TISOTT, S. T.; TONELLO, D.; MAGNI, A. A. Estudo bibliométrico em Controladoria no Congresso Brasileiro de Custos no período de 2004 a 2010. Revista de Estudos Contábeis, Londrina, v.6, n.11, p.3-22, 2015.

VASCONCELOS, G.; LIMA, A. C.. Análise bibliométrica da produção acerca da controladoria. Management Control Review, v.2, n.1. 2017.

A CBPC - Companhia Brasileira de Produção Científica (CNPJ: 11.221.422/0001-03) detém os direitos materiais desta publicação. Os direitos referem-se à publicação do trabalho em qualquer parte do mundo incluindo os direitos às renovações, expansões e disseminacões da contribuicão, bem como outros direitos subsidiários. Todos os trabalhos publicados eletronicamente poderão posteriormente ser publicados em coletâneas impressas sob coordenação da Sustenere Publishing, da Companhia Brasileira de Produção Científica e seus parceiros autorizados. Os (as) autores (as) preservam os direitos autorais, mas não têm permissão para a publicação da contribuição em outro meio, impresso ou digital, em português ou em tradução. 